See Article page 177 .

\section{Commentary: Stentless valve for bicuspid aortic valve replacement: Some answers just lead to more questions}

\author{
Charles M. Wojnarski, MD, MS, and \\ Robert J. Moraca, MD
}

In this issue of JTCVS Open, Brown and colleagues ${ }^{1}$ present a retrospective analysis of patients undergoing stentless aortic valve replacement for aortic stenosis and/or regurgitation in patients with bicuspid aortic valves (BAV) or tricuspid aortic valves (TAV). From 1992 to 2014, 1293 patients underwent stentless aortic valve replacement with modified inclusion technique at the University of Michigan and were followed for a median of 7.8 years (interquartile range, 4.2 years). The authors used propensity score matching to adjust for group differences and then performed Cox proportional hazard models and employed the Fine-Gray subdistribution method to compare survival and the cumulative incidence of reoperation due to structural valve deterioration with death as a competing risk.

This is one of the largest single-institution series to date evaluating the aortic Freestyle prosthesis (Medtronic, Minneapolis, Minn) using the modified inclusion technique of implantation and the first to differentiate outcomes stratified by valve morphology. After matching, then multivariable adjustment, the authors reported that patients with BAV had better survival (hazard ratio, $0.71 ; 95 \%$ confidence interval $[\mathrm{CI}], 0.56-0.91$, log-rank, $P=.006$ ) and similar hazard of reoperation over time (hazard ratio, 1.4; $95 \%$ CI, 0.8-2.6, log-rank $P=.27$ ). The authors also reported a greater incidence of reoperation in the patients with

\footnotetext{
From the Section of Cardiac Surgery, Department of Surgery, Virginia Mason Medical Center, Seattle, Wash.

Disclosures: The authors reported no conflicts of interest.

The Journal policy requires editors and reviewers to disclose conflicts of interest and to decline handling or reviewing manuscripts for which they may have a conflict of interest. The editors and reviewers of this article have no conflicts of interest.

Received for publication Nov 1, 2021; revisions received Nov 1, 2021; accepted for publication Nov 2, 2021; available ahead of print Nov 24, 2021.

Address for reprints: Charles M. Wojnarski, MD, MS, Virginia Mason Medical Center, 1100 Ninth Ave, X3-CAR, Seattle, WA 98101 (E-mail: charles.wojnarski@ virginiamason.org).

JTCVS Open 2021;8:191-2

2666-2736

Copyright (c) 2021 The Author(s). Published by Elsevier Inc. on behalf of The American Association for Thoracic Surgery. This is an open access article under the CC BY-NC-ND license (http://creativecommons.org/licenses/by-nc-nd/4.0/).

https://doi.org/10.1016/j.xjon.2021.11.005
}

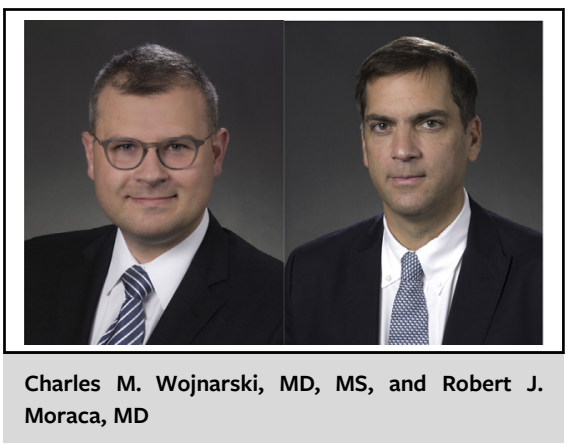

\begin{abstract}
CENTRAL MESSAGE
Anatomic and patient-specific

variation exists between patients

with bicuspid and tricuspid aortic

valves, and these differences may

impact durability of valve

replacement choice.
\end{abstract}

BAV at 15 years-15\% (95\% CI, 10\%-22\%) versus $11 \%(95 \%$ CI, 6.4\%-17\%) for patients with TAV (Gray test, $P=.05$ ). However, they chose to downplay the results of the cause-specific hazard model (above), which showed that after further adjustment for age, sex, and concomitant aortic surgery, there was no significant difference in hazard of reoperation over time between the 2 valve types.

When interpreting the results of competing risk analyses, it is important to first understand what questions are being asked of the data. If one wants to simply estimate incidence for prognostic reasons, the Fine-Gray subdistribution method is appropriate; however, if one wants to delve deeper into addressing etiologic questions (such as the impact of BAV on need for reoperation when stentless valve is implanted), then cause-specific models should be sought out. ${ }^{2}$ Fortunately, the authors have presented both for the reader. Regardless of how one interprets the findings of this report, it is important to note that anatomic and patient-specific variation exists between patients with BAV and TAV, and these differences may impact durability of valve replacement choice.

Finally, 258 patients $(20 \%)$ in this series of 1298 patients had incomplete reoperation follow-up data, perhaps limiting the reproducibility/generalizability of their conclusions. Furthermore, although the authors collected data on the reason for reoperation including valve dysfunction, valve infection, valve thrombosis, or other (such as aortic aneurysm and pseudoaneurysm), they only defined and 
reported reoperations for valve dysfunction from structural valve deterioration. Several other series with the modified inclusion technique have shown similar structural valve deterioration rates over time but have also included nonstructural valve deterioration reoperations, which may be related to the bioprosthesis choice. ${ }^{3-5}$

The group at University of Michigan has previously published on aortic valve reoperation for failed stentless bioprosthesis; interestingly, $75 \%$ of the patients in that cohort had BAV. ${ }^{6}$ This is quite higher than the established prevalence of BAV during isolated aortic valve replacement $\approx 50 \%$. This was undoubtedly the impetus for the present analysis. Rather than comparing 2 distinct pathologic states (BAV vs TAV), it may be more practical for future study to address durability of stented versus stentless bioprostheses limited to patients with BAV to further help address the authors' hypothesis.

\section{References}

1. Brown B, Le T, Naeem A, Malik A, Norton EL, Wu X, et al. Stentless valves for bicuspid and tricuspid aortic valve disease. J Thorac Cardiovasc Surg Open. 2021; $8: 177-88$

2. Austin PC, Thomas N, Rubin DB. Covariate-adjusted survival analyses in propensity-score matched samples: imputing potential time-to-event outcomes. Stat Methods Med Res. 2020;29:728-51.

3. Bach DS, Kon ND. Long-term clinical outcomes 15 years after aortic valve replacement with the Freestyle stentless aortic bioprosthesis. Ann Thorac Surg. 2014;97:544-51.

4. Mohammadi S, Tchana-Sato V, Kalavrouziotis D, Voisine P, Doyle D, Baillot R, et al. Long-term clinical and echocardiographic follow-up of the Freestyle stentless aortic bioprosthesis. Circulation. 2012;126(11 suppl 1):S198-204.

5. Amabile N, Bical OM, Azmoun A, Ramadan R, Nottin R, Deleuze PH. Long-term results of Freestyle stentless bioprosthesis in the aortic position: a single-center prospective cohort of 500 patients. J Thorac Cardiovasc Surg. 2014;148:1903-11.

6. Yang B, Patel HJ, Norton EL, Debenedictus C, Farhat L, Wu X, et al. Aortic valve reoperation after stentless bioprosthesis: short- and long-term outcomes. Ann Thorac Surg. 2018;106:521-5.

7. Roberts WC, Ko JM. Frequency of unicuspid, bicuspid and tricuspid aortic valves by decade in adults having aortic valve replacement for isolated aortic stenosis. Circulation. 2005; 111:920-5. 